Article

\title{
Carbaryl Photochemical Degradation on Soil Model Surfaces
}

\author{
Marie Siampiringue ${ }^{1,2}$, Rajae Chahboune ${ }^{1,2}$, Pascal Wong-Wah-Chung ${ }^{3}$ and \\ Mohamed Sarakha 1,2,* \\ 1 Institut de Chimie de Clermont-Ferrand, Université Clermont Auvergne, 10448, F-63000 Clermont-Ferrand, \\ France; siam@cnep-ubp.com (M.S.); rajae.chahboune@gmail.com (R.C.) \\ 2 Centre National de la Recherche Scientifique, UMR 6296, ICCF, BP 80026, F-63171 Aubière, France \\ 3 Laboratoire Chimie Environnement (LCE), CNRS UMR 7376, Aix Marseille University, F-13331 Marseille, \\ France; pascal.wong-wah-chung@univ-amu.fr \\ * Correspondence: mohamed.sarakha@uca.fr; Tel.: +334-7340-7170
}

Received: 15 December 2018; Accepted: 24 February 2019; Published: 5 March 2019

check for updates

\begin{abstract}
The phototransformation of carbaryl was investigated upon solar light exposure on three surfaces, silica, kaolin and sand, as soil models. By excitation with a Suntest set up at the surface of the three solid supports, the degradation of carbaryl followed first-order kinetics with a rate constant of $0.10 \mathrm{~h}^{-1}$. By using the Kubelka Munk model, the quantum yield disappearance at the surface of kaolin was evaluated to $2.4 \times 10^{-3}$. Such a value is roughly one order of magnitude higher than that obtained in aqueous solutions. The results indicated that the particle size and the specific surface area of the various models have significant effects. The photo-oxidative properties as well as the byproduct elucidation by liquid chromatography combined with diode arrays (LC-DAD) and liquid chromatography coupled mass spectrometry (LC-MS) analyses allowed us to propose the degradation mechanism pathways. The main products were 1-naphtol and 2-hydroxy-1,4-naphthoquinone, which arise from a photo-oxidation process together with products from photo-Fries, photo-ejection and methyl carbamate hydrolysis. The toxicity tests clearly showed a significant decrease of the toxicity in the early stages of the irradiation. This clearly shows that the generated products are less toxic than the parent compound.
\end{abstract}

Keywords: photodegradation; carbaryl; kaolinite; soil; solar irradiation

\section{Introduction}

Carbaryl, 1-naphtyl N-methylcarbamate, also known by the trade name Sevin ${ }^{\circledR}$, is distributed by the Bayer Company. It is used as a substitute for some organochloride pesticides and represents one of the most commonly used insecticides [1]. Carbaryl has been used against many harmful insects on different crops by contact [2-4]. It has also been employed in golf courses, lawns, and alandscapes for flea, lice or mosquito treatment $[5,6]$. Su ch wide range of applications is due to its ability to act as an inhibitor of cholinesterase, which is one of the main enzymes in the nervous system [7]. Thus, regarding the large amount that is spread, it has been clearly established that this compound can lead to bioaccumulation in food and water sources. Martin et al. have shown that carbaryl is one of the most commonly detected insecticides in surface waters in the U. S., while Walters et al. confirmed its presence in fish $\left(7 \mu \mathrm{g} \mathrm{L}^{-1}\right)$ and in rain runoff $\left(1737 \mu \mathrm{g} \mathrm{L}^{-1}\right)$ [8,9]. More recently, studies have established the presence of carbaryl and/or its hydrolyzed products in soils in relatively high amounts (16.3 ppm) [10-12]. Such results have prompted researchers to focus their attention on its fate in various environmental compartments [13-18]. 
It has been well described in the literature that, among the carbaryl transformation pathways in water, the hydrolysis process may play a significant role. Such efficient reaction leads to the formation of 1-naphtol as a primary product, in pure water as well as in artificial or natural waters within a couple of days [16-18]. Moreover, carbaryl may also undergo photochemical dissociation in the environment. In aqueous media, carbaryl photolysis occurs through the production of naphtoxyl radicals by homolytic scission and leads to several naphtoquinone derivatives [19]. Concerning studies on indirect photodegradation in natural waters, these highlight the role of hydroxyl radicals that were generated by nitrate ions and dissolved organic matter (DOM) [20]. Beside these studies on carbaryl behaviour in water under sunlight irradiation, to our knowledge, no work has been devoted to the phototransformation of carbaryl on soil surfaces. However, several studies have investigated its adsorption, interactions and biodegradation at the surface of clays and soils [21-26].

\section{Materials and Methods}

\subsection{Chemical}

Carbaryl (1-naphtyl-N-methylcarbamate) $(99.8 \%)$, coumarin $(\geq 99 \%)$, 1-naphtol and 2-hydroxy-1,4-naphtoquinone (97\%) were purchased from Sigma Aldrich and used without further purification. Kaolin and silica were purchased from Fluka. Sand (sand of Fontainebleau) was purchased from Labosi, and was cleaned twice with methanol $(5 \mathrm{~g}$ in $20 \mathrm{~mL})$ and dried at $80^{\circ} \mathrm{C}$ for several hours prior to use. All the other chemicals were used as received without further purification.

\subsection{Preparation of Solid Model Media Doped with Carbaryl}

\subsubsection{Kaolin Layer Samples}

The preparation of clay layers $(2.5 \mathrm{~cm} \times 1.5 \mathrm{~cm})$ was performed on Pyrex glass according to the published procedure [27]. Clay slurry and the standard solution of carbaryl ( $12.5 \mathrm{mg}$ in $25 \mathrm{~mL}$ ) were prepared in methanol solution. Accurate volumes of slurry were poured on the glass and allowed to dry for $2 \mathrm{~h}$ at room temperature (roughly $20^{\circ} \mathrm{C}$ ). The layer thickness was determined considering the dried amount of clay, surface area and kaolin bulk density $\left(1.8 \mathrm{~g} \mathrm{~cm}^{-3}\right)$ [28]. Thus, layers of various thicknesses were varied from 25 to $200 \mu \mathrm{m}$ by varying the slurry volume. Then, $0.5 \mathrm{~mL}$ of carbaryl solution was systematically and carefully poured on kaolin layer to obtain a constant concentration of carbaryl (roughly $0.25 \mathrm{mg}$ per layer) after solvent evaporation.

\subsubsection{Powder Samples}

Five grams of solid sample were added to $5.0 \mathrm{~mL}$ of a methanol solution of carbaryl $\left(2.5 \times 10^{-4}\right.$ mol L ${ }^{-1}$ ), mixed vigorously and then dried to allow the evaporation of the organic solvent. Carbaryl concentration was maintained constant at $0.5 \mathrm{mg}$ of carbaryl per gram of solid support. Three hundred milligrams of this powder were deposited on a Teflon mold supported by a glass slide to obtain a surface of roughly $1.0 \mathrm{~mm}$ thickness.

\subsection{Characterization of Solid Supports}

Particle size distribution was performed using a laser diffraction particle size analyser model Mastersizer S from Malvern Instruments in dry mode. A standard size within the range $500 \mathrm{~nm}$ to $900 \mu \mathrm{m}$ was selected. Samples were previously dried in oven for $48 \mathrm{~h}$ at $100{ }^{\circ} \mathrm{C}$ and left in a dessiccator at room temperature prior to analysis.

A Beckman Coulter sorptiometer model SA 3100 was used to obtain the specific surface areas $\left(\mathrm{S}_{\text {spec }}\right)$ and pore-size distributions using Brunauer-Emett-Teller (BET) and Barret-Joyner-Halenda $(\mathrm{BJH})$ models, respectively. Samples were previously degassed for $24 \mathrm{~h}$ under vacuum $\left(10^{-4}\right.$ torr at $100{ }^{\circ} \mathrm{C}$ ) and adsorption measurements were realized with nitrogen at $-196{ }^{\circ} \mathrm{C}$. 
A Bruker AXS X-ray fluorescence (XRF) analyser model S4 Pioneer was employed to achieve the elemental composition of the samples. The apparatus was equipped with an $\mathrm{Rh}$ anode $\mathrm{X}$-ray tube and an $\mathrm{Si}(\mathrm{Li})$ detector. The measurements were performed under vacuum with an analysis range from sodium to bromine using a standard semi-quantitative method. The samples were prepared as pressed pellets containing $9 \mathrm{~g}$ of $\mathrm{H}_{3} \mathrm{BO}_{3}$ as binder and $1 \mathrm{~g}$ of solid powder.

\subsection{Irradiation Systems}

\subsubsection{Solar Simulated Irradiation}

The system of irradiation was a device that simulated solar radiation (Suntest-CPS+, Atlas, IL, USA) equipped with a Xenon lamp. A filter allowing transmission at $\lambda>290 \mathrm{~nm}$ was used. The power was fixed to provide about $550 \mathrm{~W} \cdot \mathrm{m}^{-2}$ and the samples' temperature was controlled by a water flow $\left(\mathrm{T}=20^{\circ} \mathrm{C}\right)$.

\subsubsection{Monochromatic Irradiation at $365 \mathrm{~nm}$}

Irradiations were carried out in an elliptical stainless-steel cylinder equipped with three high-pressure mercury lamps (black lamp, Mazda MAW $125 \mathrm{~W}$ ). The lamps presenting an emission spectrum with a maximum located at $365 \mathrm{~nm}$ (97\% of the emission) were symmetrically installed and the reactor. A water-jacketed Pyrex tube (diameter of $2.8 \mathrm{~cm}$ ) containing a maximum of $50 \mathrm{~mL}$ solution was located in the centre. The solution was continuously stirred and cooled by a water flow at a temperature of $20^{\circ} \mathrm{C}$ during the entire irradiation process.

\subsection{Extraction and HPLC Analysis}

The concentrations of carbaryl in the solid samples were determined after the following extraction procedure: the entire irradiated solid sample was transferred into a vial and $4.0 \mathrm{~mL}$ of methanol were added. The solution was vigorously stirred for $10 \mathrm{~min}$ and then centrifuged at 13,500 rpm. The supernatant was then analyzed by HPLC (Waters) equipped with a diode array detector (Waters 990), two pumps (Waters 515) and an auto sampler (Waters 717). A $C_{18}$ column Nucleodur 100-5 $(250 \mathrm{~mm} \times 4.6 \mathrm{~mm}, 5 \mu \mathrm{m})$ with a Nucleodur 100-5 $\mathrm{C}_{8}$ pre-column from Macherey Nagel was used. The mobile phase was a mixture of methanol and water $(0.3 \%$ formic acid). The separation was obtained using a linear gradient $\mathrm{MeOH} /$ water $(10 / 90, v / v)$ to $100 \%$ of $\mathrm{MeOH}$ within 20 min analysis time. The flow was fixed at $1.0 \mathrm{~mL} \mathrm{~min}^{-1}$. Thirty microliters of the supernatant were injected three times. Two different samples were systematically irradiated, and the concentration of carbaryl was the average of six independent analyses. It should be pointed out that, under our experimental conditions, the extraction efficiency of carbaryl under these conditions was higher than $90 \%$.

The photoproduct identifications were carried out by LC-MS experiments realized with a Waters HPLC system (Alliance 2695) coupled to a Q-Tof mass spectrometer equipped with a pneumatically-assisted electrospray ionization source (ESI). The HPLC system was also coupled with a Waters 996 diode array detector. Chromatographic separation was achieved by using an elution program from $95 \%$ water (with $0.2 \%$ acetic acid) and $5 \%$ methanol to $5 \%$ water (with $0.2 \%$ acetic acid) and $95 \%$ methanol after $15 \mathrm{~min}$; the obtained isocratic conditions were maintained during $10 \mathrm{~min}$. The flow rate was $0.2 \mathrm{~mL} \mathrm{~min}{ }^{-1}$, the injected volume was $30 \mu \mathrm{L}$ and the column was distributed by Waters (Xterra $\mathrm{MS} \mathrm{C}_{18}, 100 \mathrm{~mm} \times 2.1 \mathrm{~mm}, 3.5 \mu \mathrm{m}$ ). The electrospray source parameters were in a positive mode: capillary voltage $3000 \mathrm{~V}$ ( $2100 \mathrm{~V}$ in negative mode), cone voltage $35 \mathrm{~V}$, extraction cone voltage $2 \mathrm{~V}$, desolvation temperature $250{ }^{\circ} \mathrm{C}$, source temperature $110^{\circ} \mathrm{C}$, ion energy $2 \mathrm{~V}$ and collision energy $5 \mathrm{eV}$. The mass resolution was set to $10^{3}$.

\subsection{Toxicity Experiments}

The toxicity tests were undertaken using kaolin layer samples (thickness $100 \mu \mathrm{m}$ ) spiked with carbaryl $\left(20.0 \mu \mathrm{mol} \mathrm{g}^{-1}\right)$ and irradiated with the Suntest. After extraction with methanol followed by 
solvent evaporation and dissolution in water, the $\mathrm{pH}$ of the carbaryl solution (initial concentration of $1.55 \times 10^{-4} \mathrm{~mol} \mathrm{~L}^{-1}$ ) was adjusted to 7.0 using buffer solution. The toxicity was then evaluated using thermal lens spectroscopy (TLS) detection with flow injection analysis (FIA) as described in the literature [29]. The FIA system is an HPLC system equipped with a pump (Shimadzu LC-10Ai, Marne La Vallee, France), two valves of injection (Rheodyne model 9010 and 7725) and a bio-analytical column containing acetylcholinesterase enzyme. To determine the enzymatic activity, an inhibition test is performed. Enzyme inhibition was calculated according to Equations (1) and (2):

$$
\begin{gathered}
A=\frac{\mathrm{a}_{\mathrm{r}}}{\mathrm{a}_{0}} \quad \text { with } \quad \mathrm{a}_{0}=\frac{\mathrm{a}_{1}+\mathrm{a}_{2}+\mathrm{a}_{3}}{3} \\
\mathrm{I}=1-\mathrm{A}
\end{gathered}
$$

where $a_{0}$ is the initial activity of enzyme (average of three measurements $a_{1}, a_{2}$ and $a_{3}$ ), $a_{r}$ is the activity of the enzyme after injection of carbaryl solution and A is the remaining activity, and I is the enzyme inhibition activity.

\section{Results}

\subsection{Photodegradation of Carbaryl on Kaolin}

In order to determine spectrophotometric features of carbaryl on solid supports, and prior to the photochemical studies, the diffuse reflexion spectra at various concentrations on a $200 \mu \mathrm{m}$ kaolin layer were recorded and analysed (Figure 1). After subtracting the spectrum of kaolin alone as reported in the literature [30], the spectra show an absorption maximum around $290 \mathrm{~nm}$. The comparison with the UV absorption spectrum of carbaryl recorded in aqueous solution [19] indicates a similar shape with a slight bathochromic shift of roughly $10 \mathrm{~nm}$. Such an effect is more likely owing to chemical and/or physical interactions between carbaryl molecules and kaolin support.

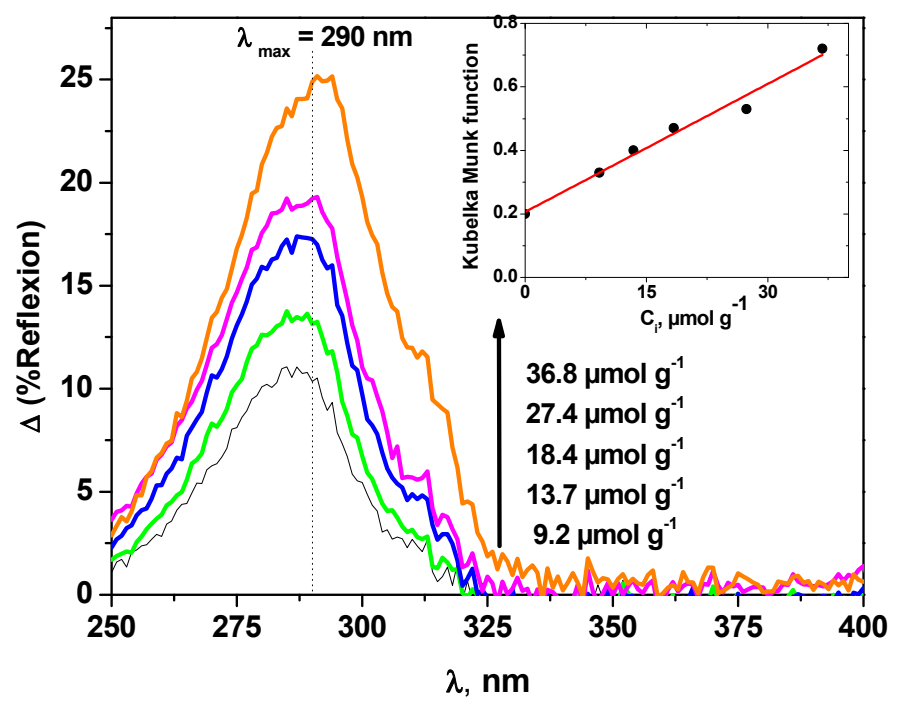

Figure 1. Diffuse reflexion spectra of carbaryl on kaolin as a function of carbaryl concentration $(200 \mu \mathrm{m}$ thickness). The inset shows the evolution of the Kubelka Munk function $f\left(R_{\infty, \text { carb }}\right)$.

The evalutation of the molar absorption coefficient $\varepsilon$ of carbaryl on the kaolin layer was obtained using the method reported in the literature [31]. For samples with a thickness higher than $200 \mu \mathrm{m}$, the Kubelka Munk model can be used [32], with the expression as follows:

$$
\mathrm{f}\left(\mathrm{R}_{\infty, \mathrm{carb}}\right)=\frac{\mathrm{k}}{\mathrm{s}}+\frac{2 \ln (10) \varepsilon_{\operatorname{carb}(\lambda)}}{\mathrm{s}} \mathrm{C}_{\mathrm{carb}}
$$


where $\mathrm{R}_{\infty, \text { carb }}$ is the reflexion of the spiked solid with carbaryl, $\mathrm{k}$ and $\mathrm{s}$ are the absorption and the scattering coefficients of kaolin, respectively, $\varepsilon_{\text {carb }}$ is the molar absorption coefficient of carbaryl at a given wavelength $\lambda$, and $C_{\text {carb }}$ is the concentration of carbaryl.

As clearly shown in the inset of Figure $1, f\left(R_{\infty, c a r b}\right)$ shows a linear relationship with $C_{\text {carb }}$ with the intercept $\mathrm{k} / \mathrm{s}$ that is in perfect accordance with published theoretical $\mathrm{k}$ and $\mathrm{s}$ values [31]. Thus, the molar absorption coefficient at $\lambda_{\max }=290 \mathrm{~nm}$ can be deduced from the slope. It was evaluated to $7.6 \times 10^{6} \mathrm{~mol}^{-1} \mathrm{~cm}^{2}$, whereas in aqueous solution, it was found equal to $5.2 \times 10^{6} \mathrm{~mol}^{-1} \mathrm{~cm}^{2}$ [19], indicating a small hyperchromic effect. As far as the overlap with the solar light emission spectrum is concerned, such an effect, associated with the bathochromic shift, is clearly in favor of an increase of the absorbance and thus of the potential photodegradability of carbaryl when deposited on the surface of solid supports.

With the aim of studying the photochemical behaviour of carbaryl on kaolin surface, layers of various thicknesses were prepared and exposed to a solar light simulator (Suntest). It should be noted that no significant reaction occurred when the samples were kept in the dark and at room temperature $\left(\mathrm{T}=20^{\circ} \mathrm{C}\right)$. Thus, under our experimental conditions, no biotic degradation occurs even though the irradiations were undertaken in non-sterilized conditions. As can be seen in Figure 2, in the absence of irradiation, the conversion of carbaryl represents less than $3 \%$ within $1 \mathrm{~h}$. This figure also shows the evolution of the concentration of carbaryl as a function of irradiation time and for five different thicknesses: $25 \mu \mathrm{m}, 50 \mu \mathrm{m}, 100 \mu \mathrm{m}, 150 \mu \mathrm{m}, 250 \mu \mathrm{m}$. The complete disappearance of carbaryl was observed for the lowest thickness within roughly $50 \mathrm{~h}$ of light irradiation, while only $30 \%$ degradation was observed for a thickness of $250 \mu \mathrm{m}$. The kinetics clearly depend on the light penetration and appear to follow first-order kinetics. The apparent first-order rate constants $\left(\mathrm{k}^{\mathrm{Z}}\right)$ as a function of the clay layer thickness are gathered in Table 1 . They appear to be proportional to $1 / Z$ within the thickness range $25 \mu \mathrm{m} \leq \mathrm{Z} \leq 100 \mu \mathrm{m}$, as highlighted by the calculation of the $\mathrm{k}^{\mathrm{Z}} \times \mathrm{Z}$. This value is constant within the given layer thickness range and evaluated as $2.40 \mathrm{~h}^{-1} \mu \mathrm{m}$. For higher $Z$ values, the rate constants rapidly decreased, likely owing to the very low carbaryl diffusion within kaolin particles.

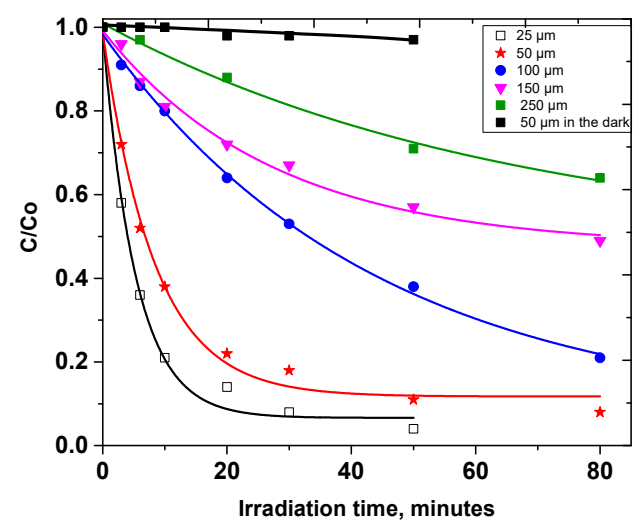

Figure 2. Photodegradation of carbaryl at the surface of kaolin for different thicknesses: $25 \mu \mathrm{m}, 50 \mu \mathrm{m}$, $100 \mu \mathrm{m}, 150 \mu \mathrm{m}, 250 \mu \mathrm{m}$, [carbaryl] $=0.5 \mathrm{mg} \mathrm{g}^{-1}$, irradiation with a Suntest setup.

Table 1. Apparent first-order rate constant of carbaryl disappearance as a function of the layer thickness: $25 \mu \mathrm{m}, 50 \mu \mathrm{m}, 100 \mu \mathrm{m}, 150 \mu \mathrm{m}, 250 \mu \mathrm{m}$, [carbaryl] $=5 \mu \mathrm{mol} \mathrm{g}^{-1}$, Suntest irradiation.

\begin{tabular}{cccccc}
\hline $\mathbf{Z}(\boldsymbol{\mu m})$ & 25 & 50 & 100 & 150 & 250 \\
$\mathbf{k}^{\mathbf{Z}}\left(\mathbf{h}^{-\mathbf{1}} \mathbf{)}\right.$ & 0.096 & 0.049 & 0.024 & 0.011 & 0.006 \\
$\mathbf{k}^{\mathbf{Z}} \times \mathbf{Z}\left(\mathbf{h}^{-\mathbf{1}} \boldsymbol{\mu \mathbf { m }}\right)$ & 2.4 & 2.5 & 2.4 & 1.7 & 1.25 \\
\hline
\end{tabular}

The constant value observed for $\mathrm{k}^{\mathrm{Z}} \times \mathrm{Z}$ is in agreement with the published following formula [27]:

$$
\mathrm{k}^{\mathrm{Z}} \times \mathrm{Z}=1.443\left(\mathrm{Z}_{0.5} \mathrm{k}^{0}\right)
$$


where $\mathrm{k}^{\mathrm{Z}}$ is the rate constant obtained for a given layer thickness, $\mathrm{k}^{0}$ is the photolysis first order rate constant at the kaolin surface and $\mathrm{Z}_{0.5}$ represents the depth for which the light intensity is divide by a factor of two. Thus, the photolytic first-order constant at the surface of the kaolin layer, $\mathrm{k}^{0}$, was estimated as $0.27 \mathrm{~h}^{-1}[27,28]$. This value permitted the calculation of the quantum yield under Suntest irradiation $(\Phi)$ using the following equation [27,33]:

$$
\mathrm{k}^{0}=2.303 \times \int_{\lambda} \phi_{\mathrm{i}} \times \mathrm{I}_{0}(\lambda) \times \varepsilon(\lambda) \mathrm{d} \lambda \Rightarrow \phi_{\mathrm{i}}=\frac{\mathrm{k}^{0}}{2.303 \times \int_{\lambda} \mathrm{I}_{0}(\lambda) \times \varepsilon(\lambda) \mathrm{d} \lambda}
$$

Under our experimental conditions, the quantum yield of carbaryl transformation was evaluated as $2.4 \times 10^{-3}$, which is roughly one order of magnitude higher than that obtained in water [19]. This result demonstrates that the photodegradation of carbaryl on the kaolin surface is much more efficient than in aqueous solutions. In order to gain a better insight into the photodegradation pathways at the surface of solid supports, further investigations were undertaken on silica and sand (sand of Fontainebleau).

\subsection{Photodegradation of Carbaryl on Kaolin, Silica and Sand}

Table 2 gathers the features of the three model supports that were used in the present work, namely kaolin, silica and sand. Considering the maximum distribution of particle diameter size, one can note that the particle size for sand is the largest, with a value of $310 \mu \mathrm{m}$, while the smallest value was obtained for kaolin $(5 \mu \mathrm{m})$.

Table 2. Some features of the solid model supports.

\begin{tabular}{cccc}
\hline & Kaolin & Silica & Sand \\
\hline Particle size $(\boldsymbol{\mu m})$ & 5 & 10 & 310 \\
Specific surface $\left(\mathbf{m}^{2} / \mathbf{g}\right)$ & 15 & 294 & 0.1 \\
Pore size $(\mathbf{n m})$ & $30-100$ & 20 & $40-150$ \\
Silicon $(\mathbf{w t}$ \%) & 54.2 & 99.1 & 95.4 \\
Iron $(\mathbf{w t}$ \%) & 2.6 & 0.00 & 0.1 \\
Titanium $(\mathbf{w t}$ \%) & 0.9 & 0.00 & 0.1 \\
\hline
\end{tabular}

Moreover, using gas adsorption technique, we confirmed the well-known high specific area of silica (up to $294 \mathrm{~m}^{2} \mathrm{~g}^{-1}$ ) but also a very low specific area for the sand, while Kaolin presents an intermediate value of $15 \mathrm{~m}^{2} \mathrm{~g}^{-1}$. One can notice that porous distributions as well as the maximum diameter size of the pores depend on the support. The porous distribution is more homogeneous for silica and centered around $20 \mathrm{~nm}$, whereas a heterogeneous distribution was observed with kaolin and sand. Two maxima were evidenced for kaolin and sand, at around 30 and $100 \mathrm{~nm}$ and around 40 and $150 \mathrm{~nm}$, respectively. The chemical composition showed that the main component for the solid model supports is silicon with a percentage of $99,95.4$ and 54.2 for silica, sand and kaolin respectively. Nevertheless, it is worth noting that traces $(<3 \%)$ of titanium and iron were also detected in kaolin and sand.

The kinetics of carbaryl disappearance on the different supports, prepared as powder samples, are represented in Figure 3. 


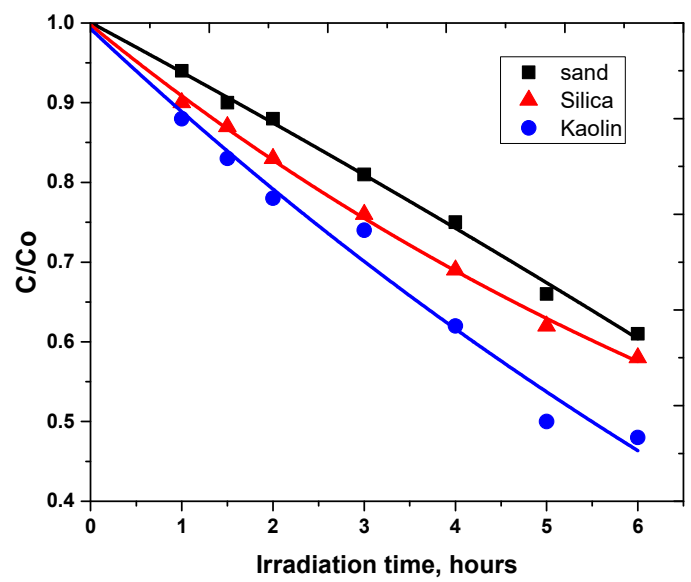

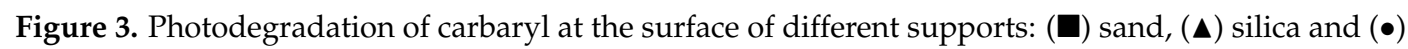
kaolin, [carbaryl] $=0.5 \mathrm{mg} \mathrm{g}^{-1}$, Suntest irradiation.

This clearly shows that the degradation rates are in the order $R_{\text {sand }}>R_{\text {silica }}>R_{\text {Kaolin }}$ (Table 3). The degradation at the surface of silica is lower than that in sand despite its highest surface area indicating that this parameter is not a crucial one. If the surface area could be in favor of high photodegradability, the low particle and pore sizes could decrease the photodegradation efficiency [34-36].

Table 3. Initial rate constants and degradation of carbaryl on different supports, [carbaryl] $=0.5 \mathrm{mg} \mathrm{g}^{-1}$, Suntest irradiation.

\begin{tabular}{cccc}
\hline & Kaolin & Silica & Sand \\
\hline $\mathbf{k}\left(\mathbf{h}^{-\mathbf{1}}\right)$ & 0.075 & 0.092 & 0.12 \\
\% of conversion after $\mathbf{5} \mathbf{h}$ & 35 & 46 & 38 \\
\hline
\end{tabular}

In fact, the high specific area is in favor of the regular distribution and dispersion of carbaryl as a monolayer on the solid support particle. This could promote the incident light penetration by reducing the screen effect of carbaryl and thus lead to an increase of the photodegradation rate. Such an effect of the specific surface area has been proved to be an important factor in the evolution of the degradation process [34]. Moreover, regarding the high sand particle size, one can presume that light scattering could be favored owing to the interparticle spaces. Both phenomena imply a deeper light penetration, inducing the increase of carbaryl photodegradation as previously described with different silica [35-38]. The low initial rate constant with kaolin can be attributed to low specific surface area and small particle size. Therefore, the carbaryl screen effect is enhanced by the hypothetical multilayer structure, while small interparticle spaces and restricted light scattering could limit incident light penetration.

\subsection{Photoinductive Properties of the Model Supports}

The chemical composition of the used model supports showed that the amount of titanium and iron, probably as oxide forms, is not negligible, in particular for kaolin and sand. The involvement of such species in carbaryl degradation through photocatalytic reactions is highly conceivable for prolonged irradiation times. In fact, light absorption by these photocatalysts is known to produce highly reactive oxygen species (ROS) such as hydroxyl radicals $\left(\mathrm{OH}^{\bullet}\right)$. These species are able to react with many organic compounds with high rate constants leading to their transformation [37,38]. As a consequence, the study of the photoinduced properties of the solid supports was undertaken to highlight the formation of hydroxyl radicals. Experiments were carried out with solid suspension in aqueous solution of coumarin in aerated medium and under irradiation at $365 \mathrm{~nm}$. This irradiation 
wavelength was selected to allow selective excitation of the solid support. $\mathrm{OH}^{\bullet}$ formation was followed by the selective fluorescence measurement at $453 \mathrm{~nm}$ of 7-hydroxycoumarin (7-HC) produced from the reaction of hydroxyl radicals with coumarin [39-41].

Under our experimental conditions, it is worth noting that the fluorescence increase is observed with all supports, confirming the generation of hydroxyl radicals (Figure 4). No relationship between the percentage of titanium and iron species and hydroxyl radical production rate can be observed. In fact, 7-HC formation is lower under irradiation with kaolin despite its highest content in titanium and iron, while 7-HC quantities produced with silica and sand after $6 \mathrm{~h}$ are similar, probably because of minor disparities in chemical composition. Moreover, no significant variation appears between the initial appearance rates of 7-HC on different supports. The results suggest that titanium and/or iron species present in the used solid supports have very low photoactivity, and we assume that the photodegradation can be attributed to other species. In fact, as previously described in the literature by Katagi for clays, the photoreactivity can be due to the solid support by an electron transfer process with molecular oxygen [42]. The electron transfer reaction with oxygen can lead to the formation of a superoxide anion $\left(\mathrm{O}_{2}{ }^{\bullet-}\right)$ which can be transformed in the presence of residual water in hydroperoxide radical $\left(\mathrm{HO}_{2}{ }^{\bullet}\right)$ and afterward in hydrogen peroxide $\left(\mathrm{H}_{2} \mathrm{O}_{2}\right)$ and hydroxyl radical. In addition, this set of experiments corroborates the kinetics of carbaryl degradation with comparable efficiency for silica and sand surfaces, but higher than for kaolin. This leads us to the conclusion that $\mathrm{OH}^{\bullet}$ radicals are probably involved in the carbaryl photodegradation processes.

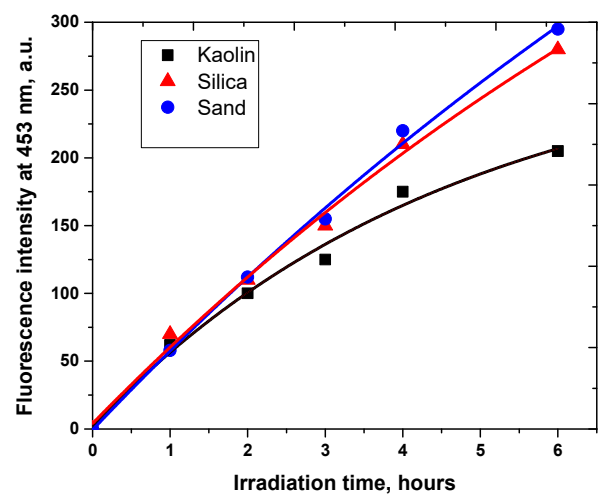

Figure 4. Evolution of the fluorescence at $453 \mathrm{~nm}$ during the irradiation of different model supports: $(\boldsymbol{\square})$ kaolin, $(\boldsymbol{\Delta})$ silica and $(\bullet)$ sand, $\left(\mathrm{c}=1.0 \mathrm{~g} \mathrm{~L}^{-1}\right)$ in the presence of coumarin $\left(9.4 \times 10^{-4} \mathrm{~mol} \mathrm{~L}^{-1}\right)$, $\lambda_{\text {exc }}=365 \mathrm{~nm}$.

\subsection{Photoproducts and Mechanisms}

The irradiation of the pesticide carbaryl at the surface of the three solid surfaces leads to the formation of several and similar by-products that were easily identified by liquid chromatography and using diode array detector. As shown in Figure 5, the Suntest irradiation at the surface of silica powder for $3 \mathrm{~h}$, permitting a conversion of roughly $25 \%$, gives rise to the formation of mainly two products, P1 and P2, with the retention times of 13.4 and $14.2 \mathrm{~min}$, respectively. Since both of them are commercial compounds, they have been formally identified and quantified by injecting standards. P1 corresponds to 2-hydroxy-1,4-naphthoquinone while P2 corresponds to 1-naphthol. The latter compound was shown to be present as an impurity and decreased with irradiation time while 2-hydroxy-1,4-naphthoquinone was obtained from the early stages of irradiation and disappeared in its turn after $3 \mathrm{~h}$ irradiation. Under our experimental conditions, P2 may be considered as the major byproduct since it represents roughly $80 \%$ of carbaryl conversion. 

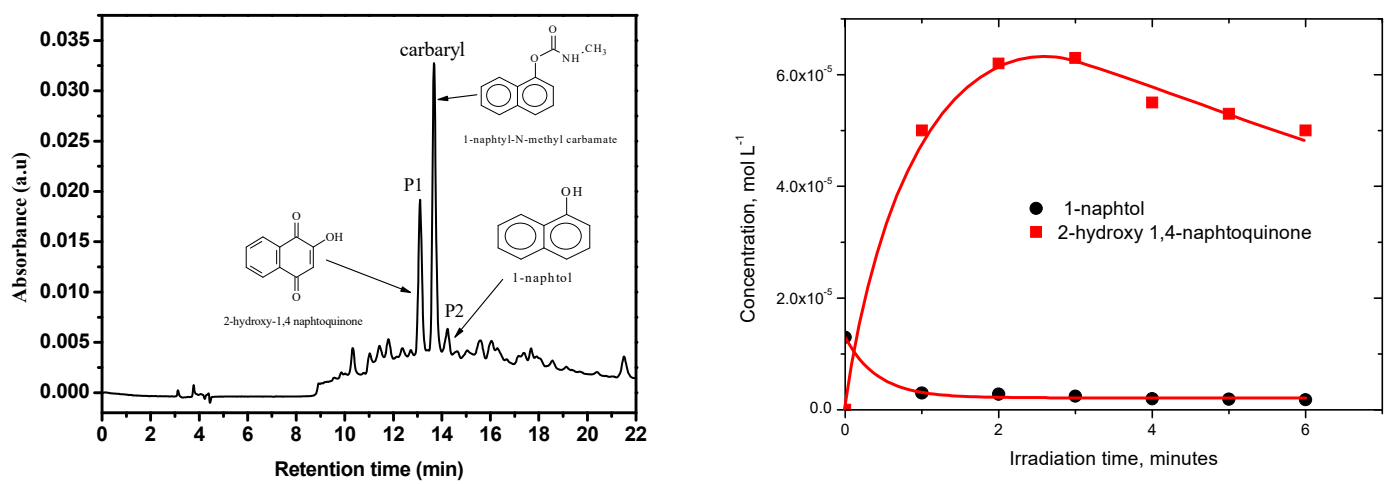

Figure 5. HPLC chromatogram of a silica powder spiked with carbaryl $\left(0.5 \mathrm{mg} \mathrm{g}^{-1}\right)$ irradiated $3 \mathrm{~h}$ in Suntest, $\lambda_{\text {detection }}=280 \mathrm{~nm}$.

In addition to P1 and P2, other photoproducts labelled as P3, P4 and P5 were detected using the sensitive technique HPLC/ESI $/$ MS. They all show retention times lower than that of the parent compound carbaryl $\left(t_{\text {ret }}=12.7 \mathrm{~min}\right)$, indicating that they are more polar. The proposed structures are gathered in Table 4.

Table 4. Proposed structure for photodegradation products of carbaryl on different support, [carbaryl] $=0.5 \mathrm{mg} \mathrm{g}^{-1}, 1 \mathrm{~h}$ irradiation in Suntest, with an electrospray ionization source (ESI) in positive mode. The elemental composition was obtained using MassLynx software. The mass resolution was set to $10^{3}$.

\begin{tabular}{|c|c|c|c|c|c|}
\hline Product & $t_{\text {ret }} \min$ & $\begin{array}{l}\text { Accurate Mass } \\
{[\mathrm{M}+\mathrm{H}]^{+}(\mathrm{m} / z)}\end{array}$ & $\begin{array}{c}\text { Elemental } \\
\text { Composition }\end{array}$ & $\begin{array}{c}\text { Mass Error } \\
\text { ppm }\end{array}$ & $\begin{array}{l}\text { Proposed } \\
\text { Structure }\end{array}$ \\
\hline Carbaryl & 12.7 & 202.0875 & $\mathrm{C}_{12} \mathrm{H}_{12} \mathrm{O}_{2} \mathrm{~N}^{+}$ & +3.4 & \\
\hline P1 & 13.4 & 175.0379 & $\mathrm{C}_{10} \mathrm{H}_{7} \mathrm{O}_{3}^{+}$ & -9.3 & \\
\hline P2 & 14.2 & 145.0663 & $\mathrm{C}_{10} \mathrm{H}_{9} \mathrm{O}^{+}$ & +6.6 & \\
\hline P3 & 11.0 & 189.0543 & $\mathrm{C}_{11} \mathrm{H}_{9} \mathrm{O}_{3}{ }^{+}$ & -4.6 & \\
\hline P4 & 9.6 & 202.0862 & $\mathrm{C}_{12} \mathrm{H}_{12} \mathrm{O}_{2} \mathrm{~N}^{+}$ & -3.0 & \\
\hline P5 & 9.4 & 218.0810 & $\mathrm{C}_{12} \mathrm{H}_{12} \mathrm{O}_{3} \mathrm{~N}^{+}$ & -3.3 & \\
\hline
\end{tabular}

Product P3 with a retention time of 11 min exhibits a protonated molecular ion $\mathrm{m} / \mathrm{z}=189$ $\left([\mathrm{M}+\mathrm{H}]^{+}\right)$. The odd mass suggests the loss of the nitrogen atom and guides us to the loss of the $\mathrm{NH}-\mathrm{CH}_{3}$ group. This could be substituted by a hydroxyl. This was confirmed by the exact mass being $m / z=189.0543$, which corresponds to $\mathrm{C}_{11} \mathrm{H}_{9} \mathrm{O}_{3}{ }^{+}$as elemental composition. Product P4 presents a protonated molecular ion $m / z=202$ similar to that of the parent substrate but a retention time of 9.6 $\mathrm{min}$, indicating the formation of an isomer of carabaryl $\left(\mathrm{m} / \mathrm{z}=202.0862 ; \mathrm{C}_{12} \mathrm{H}_{12} \mathrm{O}_{2} \mathrm{~N}^{+}\right)$. Product $\mathrm{P5}$ 
is characterized by a protonated molecular ion with $m / z=218$ that corresponds to the addition of 16 units. This more likely related to the hydroxylation of the naphthalene structure, as indicated in the proposed structure shown in Table 4 . The exact mass was $m / z=218.0810$, which corresponds to $\mathrm{C}_{12} \mathrm{H}_{12} \mathrm{O}_{3} \mathrm{~N}^{+}$as elemental composition.

As clearly shown experimentally, 1-naphtol was detected in the starting aqueous solution in small quantities prior to irradiation. It is probably the result of the well-known carbaryl hydrolysis in the dark and at room temperature [40-44]. During the irradiation process of carbaryl at the surface of the solid supports, the amount of 1-naphtol continuously decreased, likely due to an efficient photochemical [45]. Such reaction permits, via a multistep photo-oxidation processes, the formation of the secondary product 2-hydroxy-1,4-naphthoquinone which accumulates well in the medium [42] (Scheme 1).
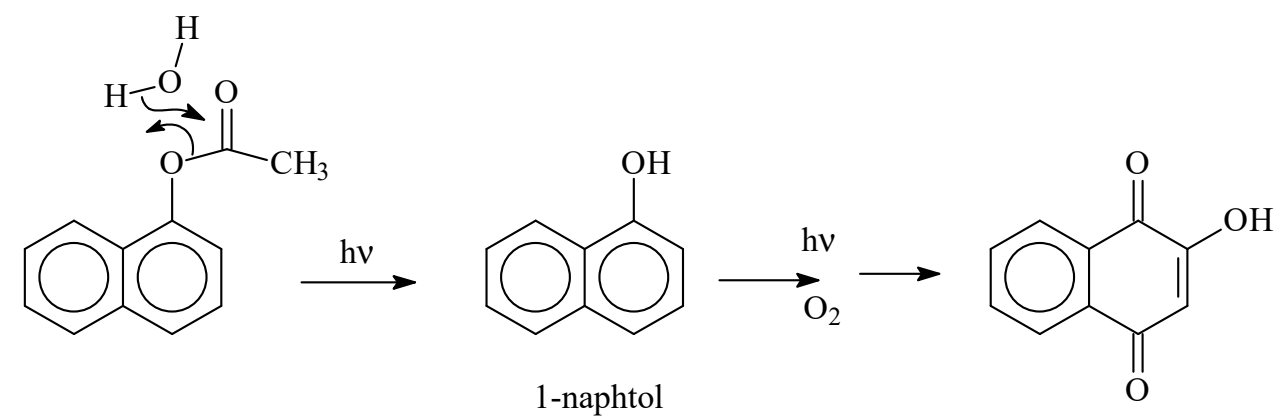

2-hydroxy-1,4-naphtoquinone

Scheme 1. Formation of 1-naphtol and 2-hydroxy-1,4-naphtoquinone by excitation of carabaryl at the surface of kaolin.

The formation of product P3 may also be obtained by the hydrolysis of the $\mathrm{NC}(=\mathrm{O})$ bond of carbaryl while product $\mathrm{P} 4$ more likely are from a photo-Fries process involving homolytic scissions of $\mathrm{C}-\mathrm{H}$ and $\mathrm{O}-\mathrm{C}(=\mathrm{O})$ bonds. Product $\mathrm{P} 5$ generation may involve hydroxyl radicals that were shown to be formed by excitation of the clays [30]. It may also be formed by an electron photoejection process via the direct excitation of carbaryl and the oxygen oxidation of the generated radical cation on the aromatic ring (Scheme 2).

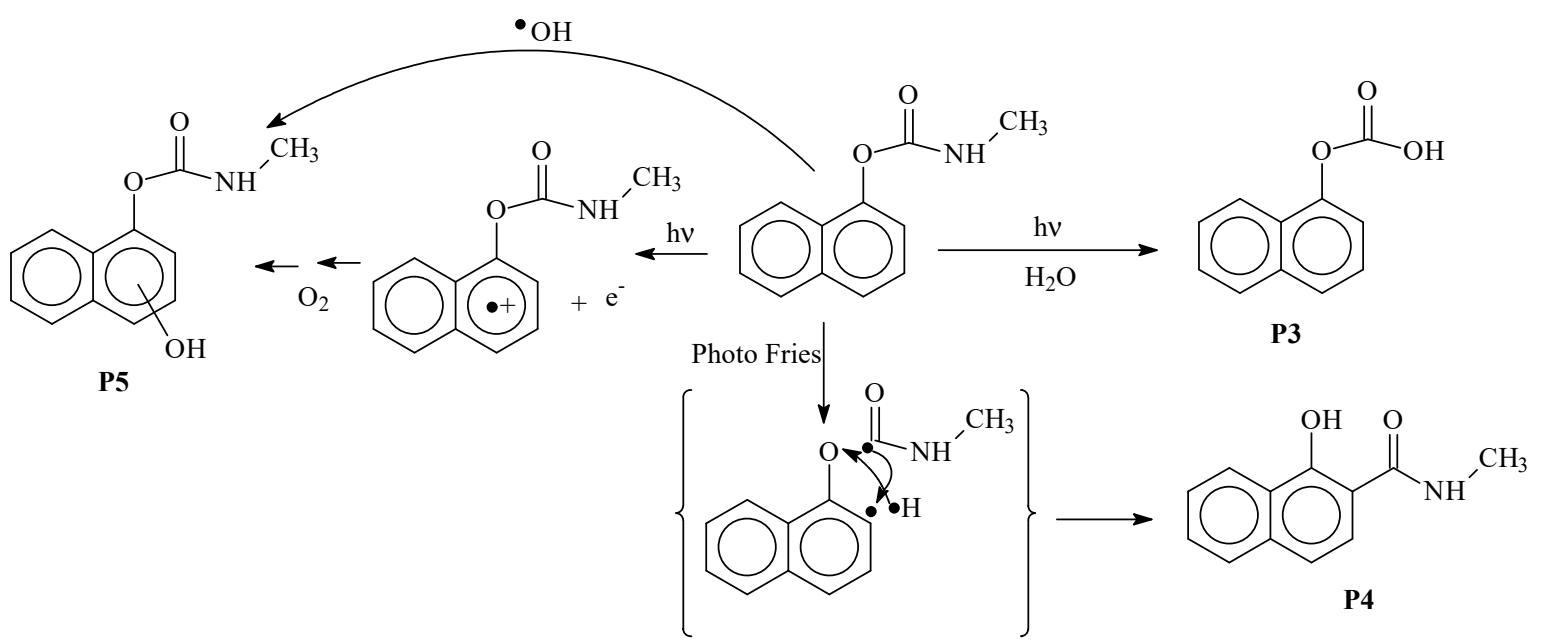

Scheme 2. Mechanistic scheme for the formation of products P3, P4 and P5.

\subsection{Toxicity Assessment}

In this part, we investigate the toxicity evolution of carbaryl on a solid support surface under solar light exposure by TLS-FIA experiments. Analyses were realized on spiked kaolin layer samples 
$(\mathrm{Z}=100 \mu \mathrm{m})$. Carbaryl disappearance kinetics as well as the evolution of AchE activity are shown in Figure 6.

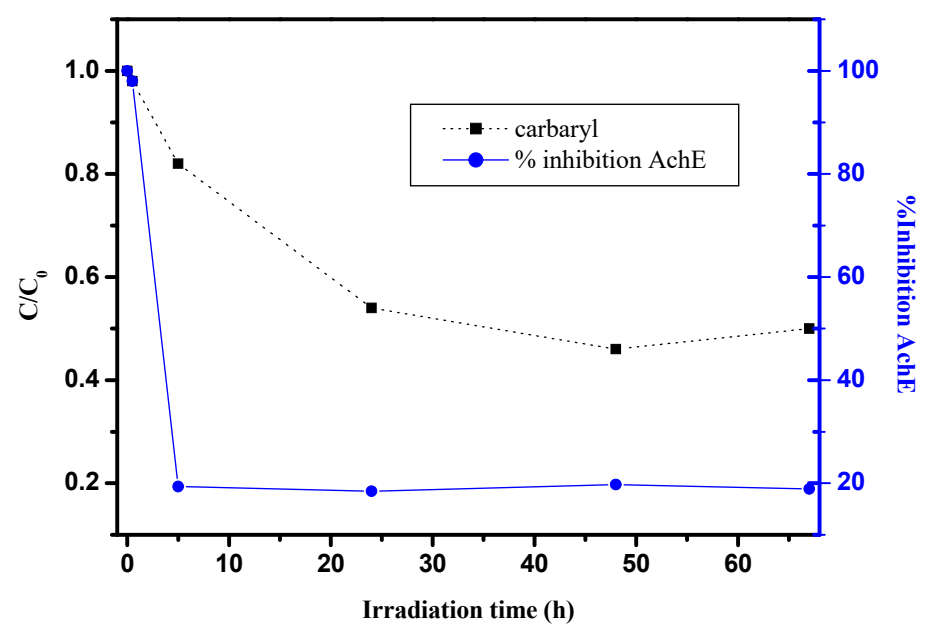

Figure 6. Evolution of AchE inhibition $(\bullet)$ and carbaryl kinetics $(\boldsymbol{\square})$ as a function of irradiation time, kaolin layer samples $(Z=100 \mu \mathrm{m})$, [carbaryl] $=20 \mu \mathrm{mol} \mathrm{g}^{-1}$, Suntest.

As clearly shown, carbaryl itself presents a relatively high toxicity since a total inhibition of AchE activity was obtained at the initial time [46-48]. Moreover, upon sunlight irradiation, the enzyme inhibition drastically decreases, more particularly within the first stages of irradiation. After $5 \mathrm{~h}$ irradiation, corresponding to about $20 \%$ conversion, AchE activity reaches the lowest value (roughly $20 \%$ ) and no evolution is observed for a longer time even if the carbaryl concentration slowly decreases. Such results clearly show that carbaryl byproducts generated on a solid surface are less toxic than the initial product.

\section{Conclusions}

Throughout this study, we clearly demonstrated that carbaryl photodegradation at the surface of the three solid supports of silica, kaolin and sand is effective. The degradation rate on the kaolin surface revealed itself to be more efficient than in water, probably because of the major modifications of carbaryl absorption properties on this surface (bathochromic and hyperchromic effects). Comparable initial rate constants were obtained for the degradation kinetics at the surface of the three supports. From the physicochemical characteristics, it appears that the main parameters controlling carbaryl photodegradation could be the particle size diameter and the specific surface area. Large particle size and high specific area promote light diffusion, and the screen effect decreases respectively, allowing a more efficient photodegradation. The formation of hydroxyl radicals with the three solid supports was evidenced in particular for silica and sand with higher amounts of radicals. Regarding the byproducts formed, various mechanistic pathways could explain the degradation of carbaryl. Some of them are comparable to that observed in water, such as photohydrolysis, electron photoejection, hydroxylation and the scission of the naphthalene ring. Moreover, we clearly give evidence for the fast decrease of carbaryl toxicity upon irradiation on the three solid surfaces from the early stages of the reaction.

Author Contributions: M.S. (Marie Siampiringue) and R.C. have been involved in the methodology; investigation and data curation; P.W.-W.-C. and M.S. (Mohamed Sarakha) have been involved in supervision, project administration, original draft; writing reviewing and editing.

Funding: This research received no external funding.

Acknowledgments: The authors would like to thank Martin LEREMBOURE for his help in the experiments in LC/MS.

Conflicts of Interest: The authors declare no conflict of interest. 


\section{References}

1. Bradbury, S. Amended Registration Decision for Carbaryl; Office of Prevention, Pesticides and TOXIC Substances, US Environmental Protection Agency: Washington, DC, USA, 2008.

2. Hastings, F.L.; Holsten, E.H.; Shea, P.J.; Werner, R.A. Carbaryl: A review of its use against bark in coniferous forests of North America. Environ. Entomol. 2001, 30, 803-810. [CrossRef]

3. Tomlin, C. (Ed.) The Pesticide Manual, 12th ed.; Crop Protection Publications: Surrey, UK, 2000; pp. 133-134.

4. Ware, G.W. The Pesticide Manual; Thomson Publication: Fresno, CA, USA, 2000; pp. 57, 83, 302.

5. Mathew, L.; Reddy, M.L.P.; Rao, T.P.; Iyer, C.S.P.; Damodaran, A.D. Simple spectrophotometric method for the determination of carbaryl in soil and insecticide formulation. Analyst 1995, 120, 1799-1801. [CrossRef]

6. Khalaf, K.D.; Morales-Rubio, A.; De la Guardia, M. Simple and rapid fow-injection spectrophotometric determination of carbaryl after liquid-liquid extraction. Anal. Chim. Acta 1993, 280, 231-238. [CrossRef]

7. Bernieri, T.; Rodrigues, D.; Barbosa, I.R.; Ardenghi, P.G.; da Silva, L.B. Occupational exposure to pesticides and thyroid function in Brazilian soybean farmers. Chemosphere 2019, 218, 425-429. [CrossRef] [PubMed]

8. Martin, J.D.; Crawford, C.G.; Larson, S.J. Pesticides in Streams-Preliminary Results from Cycle I of the National Water Quality Assessment Program (NAWQA); United States Geological Survey: Reston, VA, USA, 2003; pp. 1992-2001.

9. Walters, J.; Goh, K.S.; Li, L.; Feng, H.; Hernandez, J.; White, J.J. Environmental monitoring of carbaryl applied in urban areas to control the glassy-winged sharpshooter in California. Environ. Monit. Assess. 2003, 82, 265-280. [CrossRef] [PubMed]

10. Ni, Y.; Xiao, W.; Kokot, S. Application of chemometrics methods for the simultaneous kinetic spectrophotometric determination of aminocarb and carbaryl in vegetable and water samples. J. Hazard. Mater. 2009, 168, 1239-1245. [CrossRef] [PubMed]

11. Mauriz, E.; Calle, A.; Abad, A.; Montoya, A.; Hildebrandt, A.; Barceló, D.; Lechuga, L.M. Determination of carbaryl in natural water samples by a surface Plasmon resonance flow-through immunosensor. Biosens. Bioelectron. 2006, 21, 2129-2136. [CrossRef] [PubMed]

12. Demirbas, A. Spectrophotometric determination of carbaryl pesticide and its product in soil and strawberry samples. Sci. Total Environ. 1998, 220, 235-241. [CrossRef]

13. Carlson, R.W.; Bradbury, S.P.; Drummond, R.A.; Hammermeister, E. Neurological effects on startle response and escape from predation by medaka exposed to organic chemicals. Aquat. Toxicol. 1998, 43, 51-68. [CrossRef]

14. Juhler, R.K.; Larsen, S.; Meyer, O.; Jensen, N.D.; Spano, M.; Giwercman, A.; Bonde, J.P. Human semen quality in relation to dietary pesticide exposure and organic diet. Arch. Environ. Contam. Toxicol. 1999, 37, 415-423. [CrossRef] [PubMed]

15. Delescluse, C.; Ledirac, N.; Li, R.; Piechocki, M.P.; Hines, R.N.; Gidrol, X.; Rahmani, R. Induction of cytochrome P450 1A1 gene expression, oxidative stress, and genotoxicity by carbaryl and thiabendazole in transfected human HepG2 and lymphoblastoid cells. Biochem. Pharmacol. 2001, 61, 399-407. [CrossRef]

16. Kaline, C.C.S.; Caio, R.D.A.; Vagne, M.O.; Luiz, B.C., Jr.; Ranilson, S.B. Kinetic and physicochemical properties of brain acetylcholinesterase from the peacock bass (Cichla ocellaris) and in vitro effect of pesticides and metal ions. Aquat. Toxicol. 2013, 126, 191-197.

17. De Bertrand, N.; Barceló, D. Photodegradation of carbamate pesticides aldicarb, carbaryl and carbofuran in water. Anal. Chim. Acta 1991, 254, 235-244. [CrossRef]

18. Lars, C.; Rainer, B.; Yerbolat, S. Application of selected partial order tools to analyze fate and toxicity indicators of environmentally hazardous chemicals. Ecol. Indic. 2013, 29, 191-202.

19. Deuel, L.E.; Brown, K.W.; Price, J.; Turner, F.T. Dissipation of Carbaryl and the 1-Naphthol Metabolite in Flooded Rice Fields 1. J. Environ. Qual. 1985, 14, 349-354. [CrossRef]

20. Samanidou, V.; Fytianos, K.; Pfister, G.; Bahadir, M. Photochemical decomposition of carbamate pesticides in natural waters of northern Greece. Sci. Total Environ. 1988, 76, 85-92. [CrossRef]

21. Michelle, D.B.; Austin, S.H.; Nik, V.; Melissa, Y.; Caren, C.H. Specific time of exposure during tadpole development influences biological effects of the insecticide carbaryl in green frogs (Lithobates clamitans). Aquat. Toxicol. 2013, 130-131, 139-148.

22. Brahmia, O.; Richard, C. Phototransformation of carabaryl in aqueous solution: Laser flash photolysis and steady state studies. J. Photochem. Photobiol. A Chem. 2003, 156, 9-14. [CrossRef] 
23. Miller, P.L.; Chin, Y.P. Photoinduced degradation of carbaryl in a wetland surface water. J. Agric. Food Chem. 2002, 50, 6758-6765. [CrossRef] [PubMed]

24. Qiu, Y.; Wu, M.; Jong, J.; Li, L.; Sheng, D. Enhanced irreversible sorption of carbaryl to soils amended with crop-residue-derived biochor. Chemosphere 2013, 93, 69-74. [CrossRef] [PubMed]

25. Gupta, N.; Pillai, A.K.; Parmar, P. Spectrophotometric determination of trace carbaryl in water and grain samples by inhibition of the rhodamine-B oxidation. Spectrochim. Acta Part A 2015, 139, 471-476. [CrossRef] [PubMed]

26. Chen, H.; He, X.; Rong, X.; Chen, W.; Cai, O.; Liang, W.; Li, S.; Huang, Q. Adsorption and biodegradation of carbaryl on montmorillonite, kaolinite and goethite. Appl. Catal. Sci. 2009, 46, 102-108. [CrossRef]

27. McConkey, B.M.; Duxbury, C.L.; Dixon, D.G.; Greenberg, B. Toxicity of a PAH photooxidation product to the bacteria photobacterium phosphoreum and the duckweed lena gibba: Effect of phenanthrene and its primary photoproduct, phenanthrenequinone. Environ. Toxicol. Chem. 1997, 16, 892-899. [CrossRef]

28. Brack, W.; Altenburger, R.; Küster, Z.; Meissner, B.; Wenzel, K.D.; Schürmann, G. Identification of toxic products of anthracene photomodification in simulated sunlight. Environ. Toxicol. Chem. 2003, 22, 2228-2237. [CrossRef] [PubMed]

29. Lampi, M.A.; Gurska, J.; McDonald, K.I.C.; Xie, F.; Huang, X.D.; Dixon, D.G.; Greenberg, B.M. Photoinduced toxicity of polycyclic aromatic hydrocarbons to Daphnia magna: Ultraviolet-mediated effects and the toxicity of polycyclic aromatic hydrocarbon photoproducts. Environ. Toxicol. Chem. 2005, 25, 1079-1087. [CrossRef]

30. Balmer, M.E.; Goss, K.U.; Schwarzenbach, R.P. Photolytic transformation of organic pollutant on soil surfaces-an experimental approach. Environ. Sci. Technol. 2000, 34, 1240-1245. [CrossRef]

31. Ciani, A.; Goss, K.U.; Schwarzenbach, R.P. Light penetration in soil and particulate minerals. Eur. J. Soil Sci. 2005, 56, 561-574. [CrossRef]

32. Šikovec, M.; Novič, M.; Hudnik, V.; Franko, M. On-line thermal lens spectrometric detection of Cr(III) and $\mathrm{Cr}(\mathrm{VI})$ after separation by ion chromatography. J. Chromatogr. A 1995, 706, 121-126. [CrossRef]

33. Menager, M.; Sarakha, M. Simulated solar light phototransformation of organophosphorus azinphos methyl at the surface of clays and goethite. Environ. Sci. Technol. 2013, 47, 765-772. [CrossRef] [PubMed]

34. Ciani, A.; Goss, K.U.; Schwarzenbach, R.P. Determintation of molar absorption coefficients of organic compounds adsorbed in porous media. Chemosphere 2005, 6, 1410-1418. [CrossRef] [PubMed]

35. Kubelka, P.; Munk, F. An article on optics of paint layers. Z. Tech. Phys. 1931, 12, 593-601.

36. Ciani, A.; Goss, K.U.; Schwarzenbach, R.P. Photodegradation of organic compounds adsorbed in porous mineral layers: Determination of quantum yields. Environ. Sci. Technol. 2005, 39, 6712-6720. [CrossRef] [PubMed]

37. Chen, Y.; Wang, K.; Lou, L. Photodegradation of dye pollutants on silica gel supported $\mathrm{TiO}_{2}$ particles under visible light irradiation. J. Photochem. Photobiol. A Chem. 2004, 163, 281-287. [CrossRef]

38. Yue, Y.D.; Hua, R.M.; Tang, F.; Chen, X.Y. Effect of soil particle size on distribution and photodegradation of selected pesticides in soil. J. Anhui Agric. Univ. 1993, 20, 309-314.

39. Ahn, M.Y.; Filley, T.R.; Jafvert, C.T.; Nies, L.; Hua, I.; Bezares-Cruz, J. Photodegradation of decabromodiphenyl ether adsorbed onto clay minerals metal oxides and sediment. Environ. Sci. Technol. 2006, 40, 215-220. [CrossRef] [PubMed]

40. Feng, W.; Nansheng, D. Photochemistry of hydrolytic iron(III) species and photoinduced degradation of organic compounds. A minireview. Chemosphere 2000, 41, 1137-1147. [CrossRef]

41. Louit, G.; Foley, S.; Cabilic, J.; Coffigny, H.; Taran, F.; Valleix, A.; Renault, J.P.; Pin, S. The reaction of coumarin with the $\mathrm{OH}$ radical revisited: Hydroxylation product analysis determined by fluorescence and chromatography. Radiat. Phys. Chem. 2005, 72, 119-124. [CrossRef]

42. Katagi, T. Photoinduced oxidation of the organophosphorus fungicide toclofos methyl on clay minerals. J. Agric. Food Chem. 1990, 38, 1595-1600. [CrossRef]

43. Bianco Prevot, A.; Pramauro, E.; De la Guardian, M. Photocatalytic degradation of carbaryl in aqueous $\mathrm{TiO}_{2}$ suspensions containing surfactants. Chemosphere 1999, 39, 493-502. [CrossRef]

44. Massey, K.A.; Van Engelen, D.L.; Warner, I.M. Dtermination of carbaryl as its prilary metabolite, 1-naphtol, by reversed-phase high performance chromatography with fluorometric detection. Talanta 1995, 42, 1457-1463. [CrossRef]

45. Pramauro, E.; Bianco Prevot, A.; Vincenti, M.; Brizzolesi, G. Photocatalytic degradation of carbaryl in aqueous solutions containing $\mathrm{TiO}_{2}$ suspensions. Environ. Sci. Technol. 1997, 31, 3126-3131. [CrossRef] 
46. Anguiano, O.L.; Vacca, M.; Araujo, M.E.R.; Montagna, M.; Venturino, A.; Ferrari, A. Acute toxicity and esterase response to carbaryl exposure in two different populations of amphipods Hyalella curvispina. Aquat. Toxicol. 2017, 188, 72-79. [CrossRef] [PubMed]

47. Saxena, P.N.; Gupta, S.K.; Murthy, R.C. Comparative toxicity of carbaryl, carbofuran, cypermethrin and fenvalerate in Metaphire posthuma and Eisenia fetid. Ecotoxicol. Environ. Saf. 2014, 100, 218-225. [CrossRef] [PubMed]

48. Lima, M.P.R.; Cardoso, D.N.; Soares, A.M.V.M.; Loureiro, S. Carbaryl toxicity prediction to soil organisms under high and low temperature regimes. Ecotoxicol. Environ. Saf. 2015, 114, 263-272. [CrossRef] [PubMed]

(C) 2019 by the authors. Licensee MDPI, Basel, Switzerland. This article is an open access article distributed under the terms and conditions of the Creative Commons Attribution (CC BY) license (http:/ / creativecommons.org/licenses/by/4.0/). 